Špiro Ivošević

Romeo Meštrović

Nataša Kovač

http://dx.doi.org/10.21278/brod68404

ISSN 0007-215X

eISSN 1845-5859

\title{
AN APPROACH TO THE PROBABILISTIC CORROSION RATE ESTIMATION MODEL FOR INNER BOTTOM PLATES OF BULK CARRIERS
}

\author{
UDC 629.5.023.131: 629.546.2: 629.5.021
}

Original scientific paper

\section{Summary}

This paper gives an approach to the probabilistic corrosion rate estimation model for inner bottom plates of bulk carriers. Firstly, by using the data from thickness measurements for inner bottom plates for considered 25 bulk carriers, the related best fitted linear model for the corrosion wastage is obtained as a function of ship's age. In this model it is assumed that life of coating is 4 years. The obtained related corrosion rate is equal to $0.135474 \mathrm{~mm} /$ year. Notice that the obtained linear model is a particular case of a power model proposed in some earlier investigations.

In view of the fact that the corrosion rate of ship hull structures is influenced by many factors, many of an uncertain nature, in recent studies several authors investigated a probabilistic model as more appropriate to describe the expected corrosion. Motivated by these investigations, and using 2926 thickness measurements for corrosion wastage of inner bottom plates of considered 38 special ships surveys, this paper examines the cumulative density function for the corrosion rate $c_{1}$ involved in the mentioned linear model, and considered here as a continuous random variable. The obtained statistical, numerical and graphical results show that the logistic distribution or normal distribution would be well appropriate for the probabilistic corrosion rate estimation model for inner bottom plates of bulk carriers. It is believed that this fact will be confirmed with greater statistical reliability in our future investigations including many more data collected on the considered corrosion.

Key words: $\quad$ bulk carrier; fuel oil tanks; ship hull structure members; inner bottom plates; corrosion; probabilistic corrosion rate estimation model; normal distribution; logistic distribution

\section{Introduction}

Up to now, in many published articles, authors identify corrosion, fatigue cracking and local dent as most influenced mechanisms of age related deterioration [1]. Among many different type of vessels, bulk carriers and tankers were recognised as more critical, due to a 
lot of casualties in the last few decades. Much research focuses on degradation of aged bulk carrier members and identify corrosion as long-term degradation mechanism on ships integrity as it was presented in papers [2] and [3]. Bulk carriers are in continual contact with salt water, and simultaneously exposed to some unpredictable atmosphere, cargo and ballast effects. More precisely, aggressive environment, specifics of trade routes, dry and wet ballast circles, ratio of ballast and cargo, frequencies of cargo loading/unloading operations, etc., often affected serious bulk carriers' corrosion deteriorations [4, 5]. It is also to be emphasized that the corrosion might be aggravated by the negative effects of some cargoes, especially those like iron ore and coil $[2,4,6]$.

In previous research, authors were motivated to investigate corrosion degradation of some specific structural members such as transversal bulkhead of bulk carriers [7] or deck plating of tankers $[8,9,10,11]$, or all structural members (see Paik et al. $[4,12,13]$ ).

\subsection{Subject of research}

For the purpose of this research work, a large data base has been provided by the recognized ultrasonic measurements used from the INVAR-Ivošević Company (see Acknowledgement) during the last fifteen years. These data were collected through numerous standardized and very detailed measurements over almost all hull structure members of the group of analyzed aged bulk carriers. The present paper analyzes only gauging taken from Special Survey, which was done after every 5 years of exploitation.

However, in this article, only bulk carriers' fuel tanks time-dependent deteriorations caused by the general corrosion have been analyzed. The main reason for this lies in the fact that such kind of a problem is not covered by the previous research works in the field. Previous research covered mostly cargo holds and ballast tanks $[6,7,15,16]$.

The research in this paper is a continuation of previous research of both short and long term corrosion investigations on fuel oil tanks [14]. Monte Carlo simulation method has been used for assessing the value of damaged steel, expressed in percentage of the standard steel thickness, and Weibull probability analysis is used upon some cumulative negative timedependent fuel tanks corrosion effects in long terms, i.e., during the whole period of their exploitation [14].

\subsection{The input data set brief description}

Although the fuel tanks may be found either in the top-side tanks, or deep tanks, the subject of this paper concerns only oil (fuel) tanks placed in double bottom. Usually, these oil tanks are spatially positioned along the main axis of the bulk carrier, but they can be placed perpendicularly on it as well (Figure 1).

The total of 25 aging bulk carriers ranging from 5 to 25 years of age are investigated. All monitored bulk carriers were measured during the special surveys which were done after $5,10,15,20$ or 25 years of exploitation life cycle. In that sense, some of the bulk carriers were monitored two or three times during the previous 15 years, between 2005 and 2017. Finally, measuring data from 38 different special surveys were collected. 
An approach to the probabilistic corrosion rate estimation model for inner bottom plates of bulk carriers
Špiro Ivošević, Romeo Meštrović, Nataša Kovač

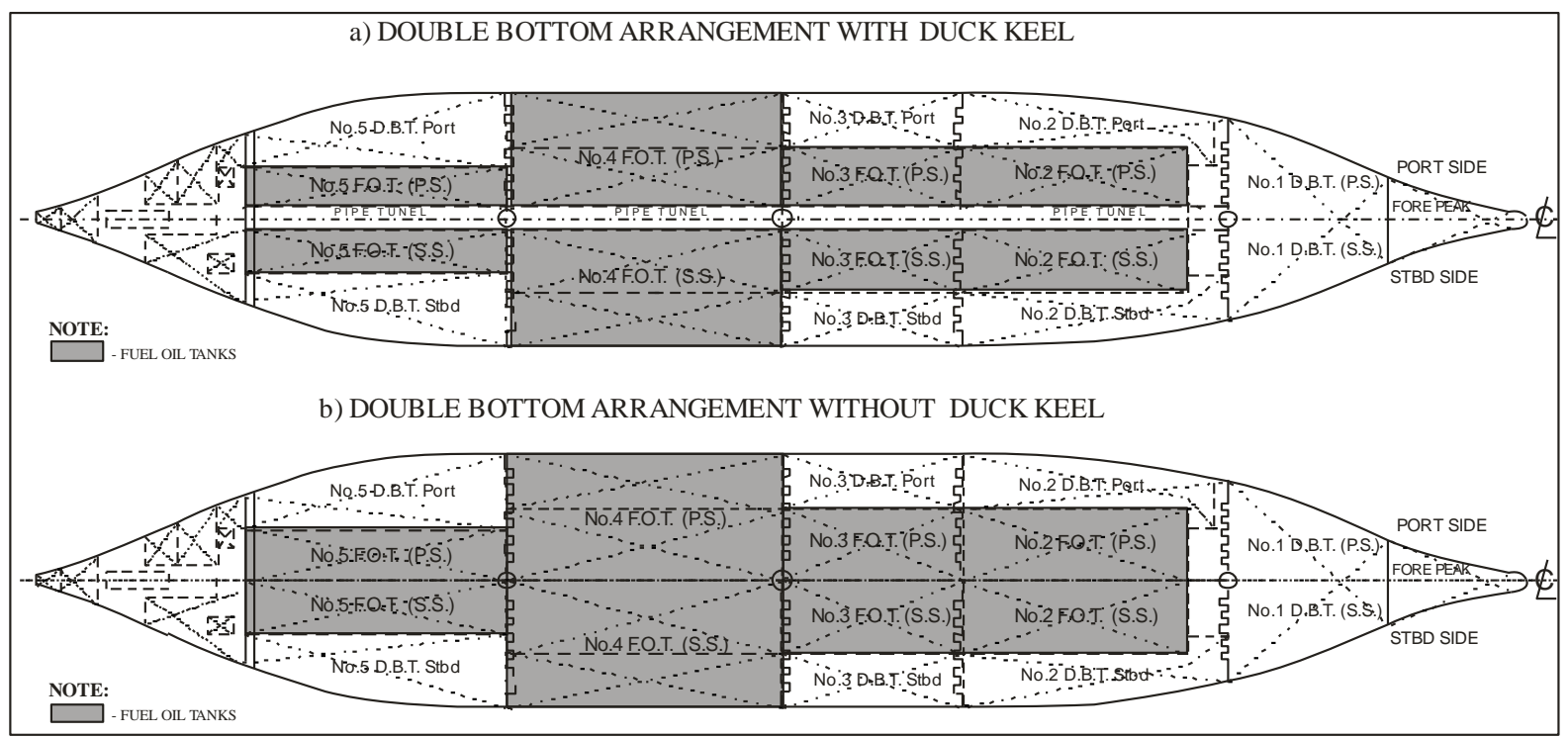

Fig. 1. Bulk carriers' different arrangements of fuel tanks: a) double bottom with duck keel, b) double bottom without duck keel (Fuel oil tanks No.4 are wide to the shell plate)

In accordance with the corrosion measuring standards and some characteristics of operational parameters, the fuel tanks of bulk carriers are considered here through ten different segments, areas, or member locations. The analysed segments are presented schematically and listed below in the form of the legend in Figure 2.

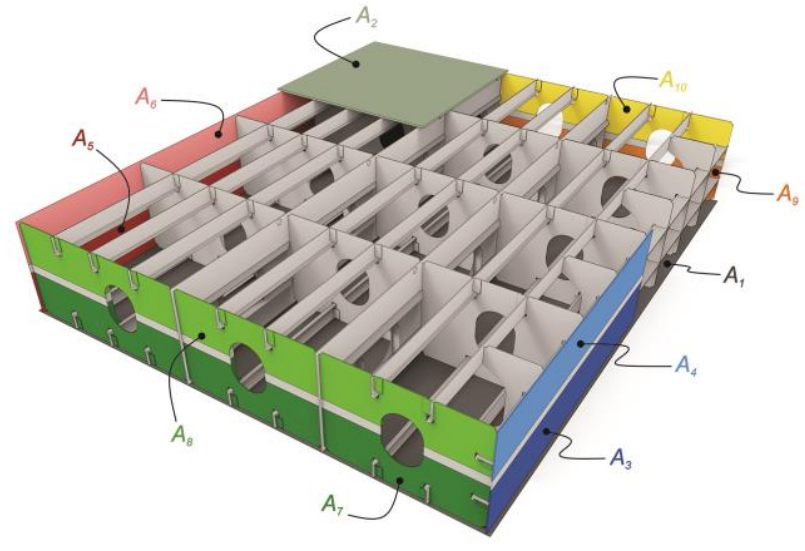

Legend:

$\mathrm{A}_{1}$ - Bottom plate

$\mathrm{A}_{2}$ - Inner bottom plate

$\mathrm{A}_{3}$ - Inside girder (water tight), lower

$\mathrm{A}_{4}$ - Inside girder (water tight), upper

$\mathrm{A}_{5}$ - Side (water tight) girder, lower

$\mathrm{A}_{6}$ - Side (water tight) girder, upper

$\mathrm{A}_{7}-$ Floor after (water tight), lower

$\mathrm{A}_{8}-$ Floor after (water tight), upper

$\mathrm{A}_{9}$ - Floor fore (water tight), lower

$\mathrm{A}_{10}$ - Floor fore (water tight), upper

Fig. 2. Basic structural scheme of a bulk carrier's fuel tank areas $\left(A_{1}-A_{10}\right)$

The data on the general corrosion loss expressed in millimetres $(\mathrm{mm})$ of steel thickness, were collected through regular measurements (surveys on site). The data are gathered over each of the previously mentioned areas $\left(\mathrm{A}_{1}-\mathrm{A}_{10}\right)$ of the fuel tanks, through 10 or 20 different sections, depending on the number of fuel tanks, for both the left, or portside $(\mathrm{P})$ and the right, or starboard (S) sides of considered bulk carriers. The data were collected during regular special surveys, in a way that each tank is divided into 5 sections: two sections for after and fore ends, and three sections at equal mutual distances in the middle, between ends of tanks. In total, 71 different fuel oil tanks are covered with sets of 570 measurements data with totally 2926 measuring points (one set of data includes all measuring points from each plate in corresponding transversal sections).

This paper gives an approach to the probabilistic corrosion rate estimation model for inner bottom plates (area $A_{2}$ ) of bulk carriers. The investigated model uses collected thickness measurements data for inner bottom plates of considered 38 ship's surveys, which were presented in Figure 3. 


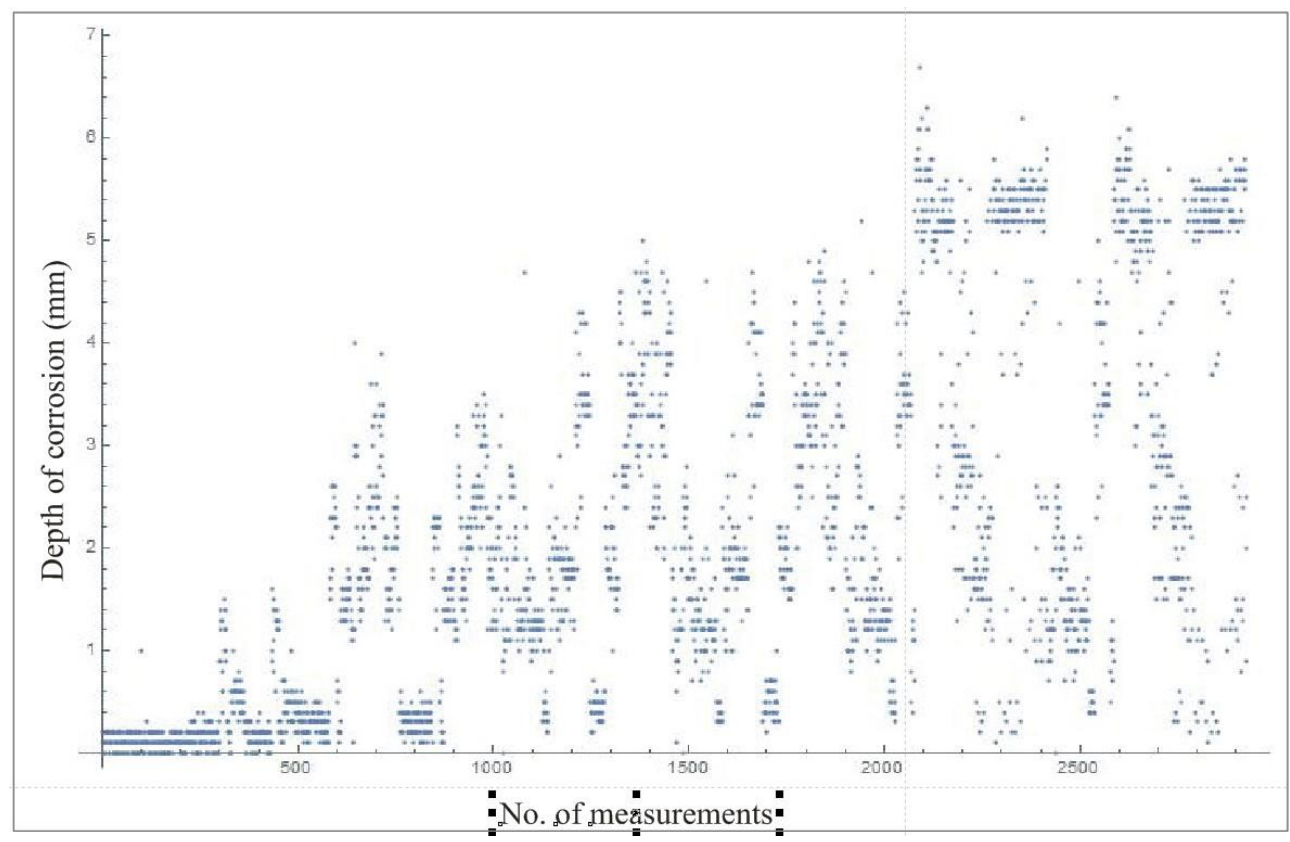

Fig. 3 Data of 2926 tthickness measurements for inner bottom plates of considered 38 ship's surveys

Figure 3 shows the raw data obtained from 2926 measurements related to the corrosion wastage for all inner bottom plates of considered 38 ship's surveys whose age was taken in the following intervals: 0-5 years, 5-10 years, 10-15 years, $15-20$ years and 20-25 years. The $x$ - axis shows how many measurements, i.e., the $x$-coordinate presents the number of the measurements, while the $y$-axis presents the values of related corrosion wastage (the depth of corrosion). These data are sorted and displayed chronologically by years (i.e., the following right bounds of the previous intervals are assumed: 5, 10, 15, 20 and 25 years). Because of that fact, the graph also points to the increasing tendency of corrosion wastage depending on the age of the ship.

This paper is organized as follows. Section 2 firstly gives a motivation for this study consisting in short survey of investigations of the analytic and probabilistic corrosion rate estimation model related to the ship hull structure. The attention is focused on this study related to corrosion wastage of inner bottom plates of bulk carriers. This investigation is also motivated by the additional well known fact that in general, the corrosion rate would be different for all ship hull structure elements. For example, inner bottom plates are exposed on one side to ballast water, dry space, fuel tanks, while on the second ones to cargo.

For bulk carriers considered here, fuel is located inside the bottom of a tank, so that corrosion comes only from a cargo hold, i.e., on top of the sheet. Thus, corrosion is measured from the cargo hold but not from the tank. It is pointed out that the selected area forms only a part of inner bottom plates and this is the part that on the bottom side is not exposed to the influence of air (dry area) or to ballast water (ballast tanks), and therefore, data may vary and they show a different distribution than those so far registered in [12].

By using the averages of data from thickness measurements for inner bottom plates of 38 considered ships surveys, in Section 2 the well suitable fitted linear model for the corrosion wastage is established. Next by using set of 570 measurements data of corrosion wastage of plate thickness for inner bottom plates of considered 38 ships surveys, the cumulative density function for the annual corrosion rate (random variable) $c_{1}$ (in mm/year) is examined, involving in the obtained linear fitted model of the form $d(t)=c_{1}(t-4)$, where $d(t)$ is the corrosion wastage as a function of ship age $t$. 
An approach to the probabilistic corrosion rate estimation model for inner bottom plates of bulk carriers
Špiro Ivošević, Romeo Meštrović, Nataša Kovač

While most authors assumed that corrosion starts after more than 5 years of newbuilding (see, e.g., [10] and [11], where deck plates and ballast tanks are considered), in this paper, it is assumed that corrosion starts after 4 years of newbuilding. This is justified on the basis of the known fact that the inner bottom plating is under constant contact of cargo inside cargo holds, under the influence of handling equipment and under the maintenance process which includes cleaning before and after cargo operations.

Related statistical, graphical and numerical results show that the logistic distribution or normal distribution (both determined with two parameters) could be very appropriate for probabilistic corrosion rate estimation model concerning inner bottom plates of bulk carriers. Notwithstanding the fact that this set of 570 measurements data is small in statistical terms for confirming this hypothesis with a sufficient level of confidence, it is believed that, by using the same analytical and statistical approach as presented here, this hypothesis will be confirmed in future investigations involving mach more data collected in respect to the considered corrosion wastage.

Concluding remarks and subject for further research are given in Section 4.

\section{Motivation for research and preliminary results}

For a good survey of investigations of the analytic and probabilistic corrosion rate estimation model for different hull structure elements of bulk carriers see the survey paper by Qin and Cui [17].

It is well known that the corrosion wastage, $d(t)$, may be generally expressed as a power function of the time (usually expressed in years) after the corrosion starts (see e.g., [17] and [18]), i .e.,

$$
d(t)=c_{1}\left(t-T_{c l}\right)^{c_{2}},
$$

where $d(t)$ is the corrosion wastage; $t$ is the elapsed time after the plate is used; $T_{c l}$ is life of coating; $c_{1}$ and $c_{2}$ are positive real coefficients. This model was proposed in [18]. The coefficient $c_{2}$ may be usually assumed to be $1 / 3$ or pessimistically assumed to be 1 , while the coefficient $c_{1}$ is indicative of the annual corrosion rate. As noticed in [17], in most of the studies on time-dependent reliability of ship structures (see, e.g., [19]-[23]), the effect of corrosion was represented by an uncertain but constant corrosion rate, which resulted in a linear decrease of plate thickness with time. However, several authors established that experimental evedince often show that some nonlinear model is more appropriate, such as Extended Southwell bilinear model, Melchers-Southwell nonlinear model, Melchers trilinear model, Melchers power model, the model proposed by Guedes Soares and Garbatov, and the model proposed by Qin and Cui (for more details on these models, see [17]).

Here the validity of the expression (1) with $c_{2}=1$ proposed by Paik, Kim and Lee [4] is verified, and as noticed above, it assumes $T_{c l}=4$ years (i.e., $d(t)=c_{1}(t-4)$ ) for the corrosion data related to inner bottom plates of considered 38 ships surveys. These measurements data are used from the INVAR-Ivošević Company. Notice that this linear model with other values of coefficient $c_{1}$ and the value $T_{c l}$ was proposed by Paik and Thayamballi [18]. In order to determine the approximate value of $c_{1}$, the values of averages of corrosion wastage are used, $d(t)$, at age $t$ (depth of corrosion in $\mathrm{mm}$ ), for inner bottom plates of 38 ship's surveys, as it is presented in Table 1 . 
Špiro Ivošević, Romeo Meštrović, Nataša Kovač
An approach to the probabilistic corrosion rate estimation model for inner bottom plates of bulk carriers

Table 1 Averages of plate thickness due to corrosion, $d(t)$ (depth of corrosion in mm), for inner bottom plates of 38 ships surveys

\begin{tabular}{|c|c|c|c|c|c|c|c|c|c|c|c|c|c|c|c|}
\hline $\begin{array}{c}\text { Ship's age } \\
\text { (in year) }\end{array}$ & $\begin{array}{c}\text { Number } \\
\text { of ship's } \\
\text { surveys }\end{array}$ & $\begin{array}{c}\text { Ship } \\
1\end{array}$ & $\begin{array}{c}\text { Ship } \\
2\end{array}$ & $\begin{array}{c}\text { Ship } \\
3\end{array}$ & $\begin{array}{c}\text { Ship } \\
4\end{array}$ & $\begin{array}{c}\text { Ship } \\
5\end{array}$ & $\begin{array}{c}\text { Ship } \\
6\end{array}$ & $\begin{array}{c}\text { Ship } \\
7\end{array}$ & $\begin{array}{c}\text { Ship } \\
8\end{array}$ & $\begin{array}{c}\text { Ship } \\
9\end{array}$ & $\begin{array}{c}\text { Ship } \\
10\end{array}$ & $\begin{array}{c}\text { Ship } \\
11\end{array}$ & $\begin{array}{c}\text { Ship } \\
12\end{array}$ & $\begin{array}{c}\text { Ship } \\
13\end{array}$ & $\begin{array}{c}\text { Averages of } \\
\text { plate thickness } \\
\text { (in mm) }\end{array}$ \\
\hline $0-5$ & 4 & 0.1 & 0.1 & 0.1 & 0.1 & & & & & & & & & & 0.1 \\
\hline $5-10$ & 4 & 0.2 & 0.1 & 0.8 & 0.5 & & & & & & & & & & 0.4 \\
\hline $10-15$ & 7 & 0.3 & 0.3 & 1.5 & 1.4 & 2 & 2.8 & 1.9 & & & & & & & 1.4571 \\
\hline $15-20$ & 13 & 1.6 & 1.4 & 0.9 & 1.8 & 1.7 & 3.5 & 0.5 & 0.4 & 1.8 & 3.3 & 3.8 & 2.9 & 3 & 2.0462 \\
\hline $20-25$ & 10 & 1.8 & 1.5 & 1 & 3.5 & 4.7 & 4.7 & 3 & 2 & 4.2 & 4.3 & & & & 3.07 \\
\hline
\end{tabular}

Here, as always in the sequel, for related computational purposes, the software Mathematica 9 is used. By using the average data given in the last column of Table 1, the following best fitted linear model for $d(t)$ is obtained (see Figure 4):

$$
d(t)=0.135474(t-4)
$$

where it is supposed that the corrosion starts 4 years after newbuilding. From Eq. (2) it follows that the related corrosion rate, $r(t)$, is equal to

$$
r(t)=d^{\prime}(t)=0.135474
$$

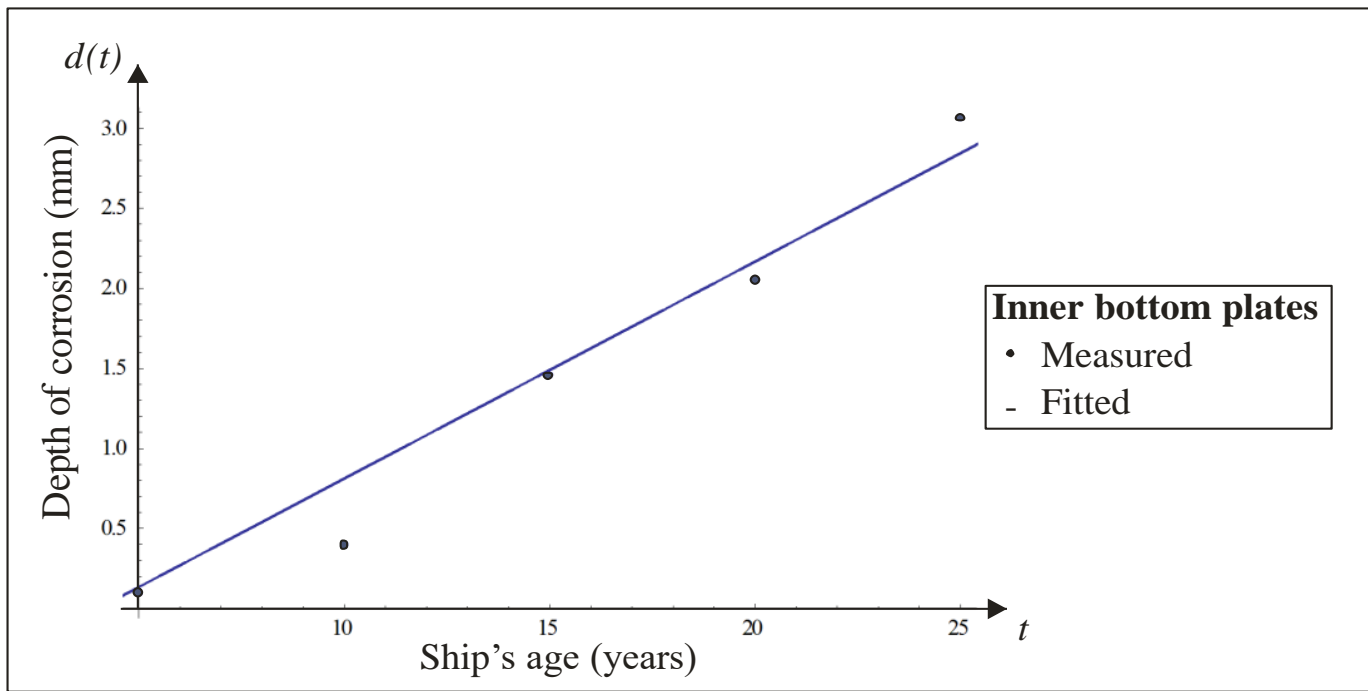

Fig. 4 Linear fitted model for data of Table 1

The following information was obtained about the parameter estimates: standard error $=$ 0.00832602 , t-statistic $=16.2711$ and $\mathrm{p}$-value $=0.0000834878$ show that the expression $(2)$ is very appropriate for determining $d(t)$ (depth of corrosion) for inner bottom plates of bulk carriers. In particular, it can be seen from Eq. (3) that the corrosion rate is a constant equals to 0.135474 .

Because the corrosion is a function of many variables, many of an uncertain nature, a probabilistic model is more appropriate to describe the expected corrosion (for more details see [17]). In particular, based on the probabilistic model proposed by Yamamoto et al. [24], [25] and Paik et al. [4], it was usually assumed that the probability density function of the corrosion rate follows the Weibull distribution. Hence, the cumulative distribution function and the probability density function of the coefficient $c_{1}$ from Eq. (1) are respectively given by 
An approach to the probabilistic corrosion rate estimation model for inner bottom plates of bulk carriers
Špiro Ivošević, Romeo Meštrović, Nataša Kovač

$$
\begin{aligned}
& F_{c_{1}}(x)=1-\exp \left(-\left(\frac{x}{w}\right)^{k}\right) \\
& f_{c_{1}}(x)=\frac{k}{w}\left(\frac{x}{w}\right)^{k-1} \exp \left(-\left(\frac{x}{w}\right)^{k}\right),
\end{aligned}
$$

where $w$ is the unknown scale parameter and $k$ is unknown shape parameter. By using the least-squares method, the unknown parameters $w$ and $k$ can be determined from the corrosion data collected.

Motivated by the above considerations, the following section studies the probabilistic corrosion rate estimation model related only for inner bottom plates of bulk carriers.

\section{The estimation of cumulative distribution function of corrosion rate $c_{1}$}

This section proposes a statistical approach for approximating the cumulative distribution function of corrosion rate $c_{1}$ defined in the previous section, but considered here as a continuous random variable.

\subsection{The appropriate statistical data related to measurements on inner bottom plates}

Total set of 570 measurements of plate thickness due to corrosion, $d(t)$ (depth of corrosion in $\mathrm{mm}$ ), for inner bottom plates of considered 38 ships surveys are graphically presented in Figure 5.

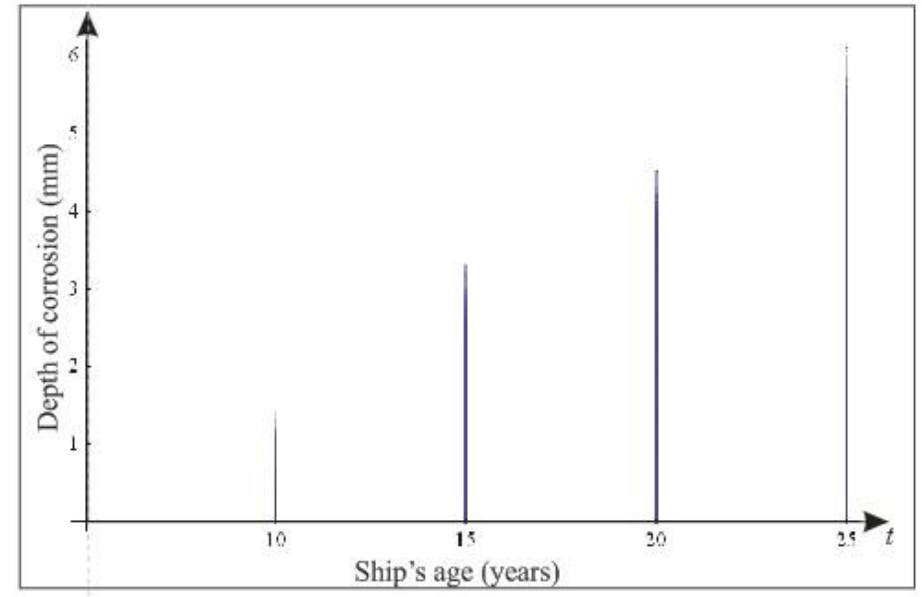

Fig. 5 Set of 570 measurements of plate thickness due to corrosion

for inner bottom plates of 38 ships surveys

A calculation based on the mentioned set of 570 measurements data shows that the average ships age is equal to 18.29 years, while the related average depth is equal to 1.91982 $\mathrm{mm}$. Their standard deviations are respectively equal to 5.95933 years and $1.49155 \mathrm{~mm}$.

Further, using a set of 570 mentioned measurements data, as in the previous section the following more refined fitted linear model for $d(t)$ than those given by (2) is obtained:

$$
d(t)=0.13679(t-4)
$$

Related standardized residuals and fit residuals are presented in Figure 6. 
Špiro Ivošević, Romeo Meštrović, Nataša Kovač

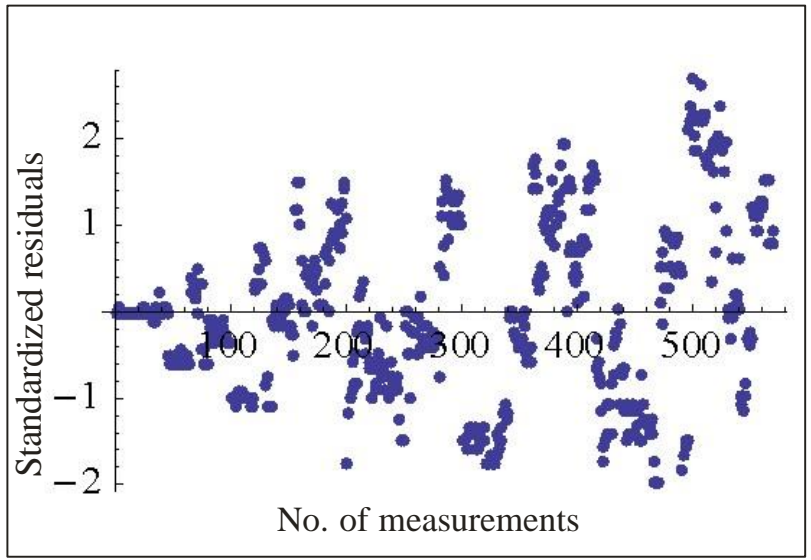

Fig. 6 a) Extract and plot the standardized residuals
An approach to the probabilistic corrosion rate estimation model for inner bottom plates of bulk carriers

\subsection{The estimation of a suitable cumulative distribution function of corrosion rate $c_{1}$}

Since the constant $c_{1}=0.13679$ from Eq. (6) "analytically" presents the related corrosion rate, which in practice is not an absolute constant, it can be considered as a continuous random variable. As noticed above, in several related investigations it is assumed that $c_{1}$ follows a (three-parametric) Weibull distribution. The collections of thickness measurements of ship hull structure members are assumed to be independent of the choice of type of this member. In view of this fact and the above mentioned fact that the corrosion rate would be different from each ship hull structure member, it can be of interest to consider the same problem concerning only any fixed ship hull structure element. As noticed above, for these purposes, a set of 570 measurements of plate thickness due to corrosion, for inner bottom plates of considered 38 ships surveys is considered here.

Assuming that in view of the above assumptions and considerations, the fitted linear model for $d(t)$ of the form $d(t)=\mathrm{c}_{1}(t-4)$ is statistically well-accepted, in order to examine the cumulative distribution function (in the sequel briefly written as CDF) of (a continuous random variable) $c_{1}$, it is needed to calculate the previously mentioned 570 statistical data for $c_{1}$ needs to be calculated by using the expression

$$
c_{1}=\frac{d(t)}{t-4} \text {. }
$$

By sorting the obtained data, they can be presented in Figure 7.

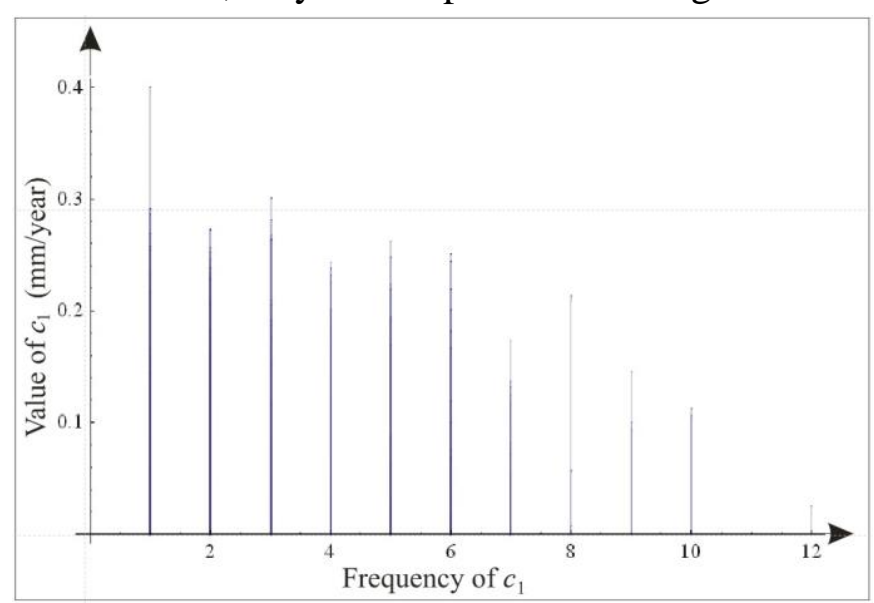

Fig. 7 The sorted values $\mathrm{c}_{1}=d(t) /(t-4)$ with related frequencies related to the set of 570 measurements of plate thickness due to corrosion 
An approach to the probabilistic corrosion rate estimation model for inner bottom plates of bulk carriers
Špiro Ivošević, Romeo Meštrović, Nataša Kovač

Under these sorted data, mean of $c_{1}$ is equal to $0.12914 \mathrm{~mm} / \mathrm{year}$ and its standard deviation is equal to $0.07685895 \mathrm{~mm} /$ year.

Now, relative frequencies (empirical PDF) related to the sorted data that correspond to Figure 7 in the intervals with step 0.02, i.e., the intervals of the form $[a, a+0.02)$ with $a=0.02,0.04, \ldots, 0.38$ can be calculated, where the middles of related intervals are assumed for the first coordinate. Related histograms are shown in Figure 8.

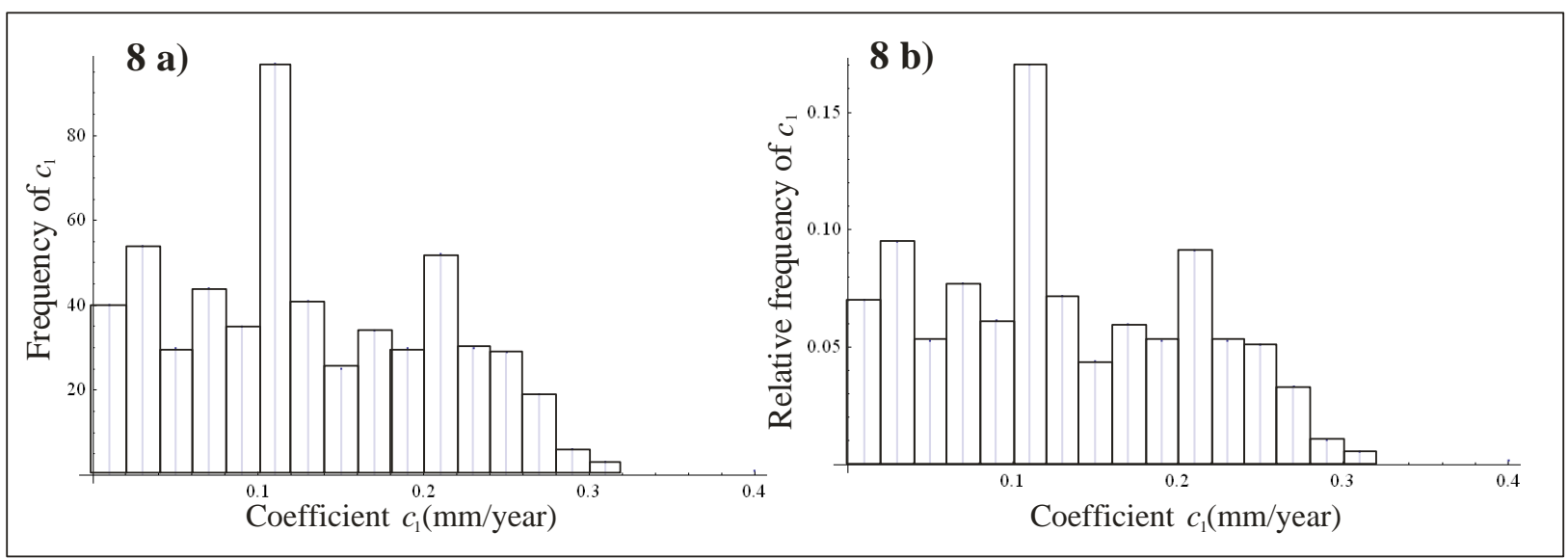

Fig. 8 Frequencies and relative frequencies of $c_{1}\left(c_{1}=d(t) /(t-4)\right)$ related to the set of 570 measurements data of plate thickness due to corrosion

The empirical CDF for the values $c_{1}=d(t) /(t-4)$ given in Figure $\left.8 \mathrm{~b}\right)$ is presented in Figure 9.

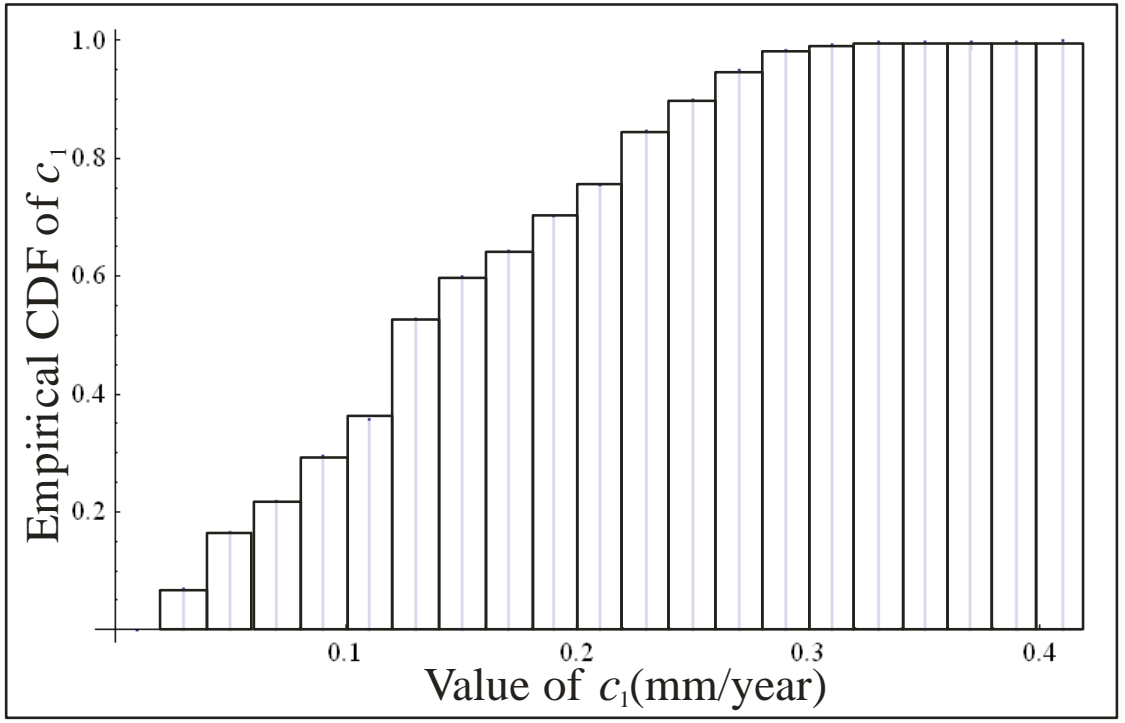

Fig. 9 The empirical CDF of the coefficient $c_{1}$ related to

the set of 570 measurements data of plate thickness due to corrosion

Now, by using the data presented in Figure 9, the corresponding fitted linear model for $\mathrm{CDF}$ of (random variable) $\mathrm{c}_{1}$ is obtained. Related obtained computational results show that Weibull distributtion does not correspond to the estimation of CDF of $\mathrm{c}_{1}$, while testing CDF of many other continuous random variables it is indicated that one or some of the following 
four distributions should be served as a best fitted distribution for $\mathrm{c}_{1}$ : normal distribution, logistic distribution, beta distribution and gamma distribution (for a visual comparison of empirical data from Figure 9 and $\mathrm{CDF}$ of these four potential well fitted distributions, see Figures 10 a)-10 d)).

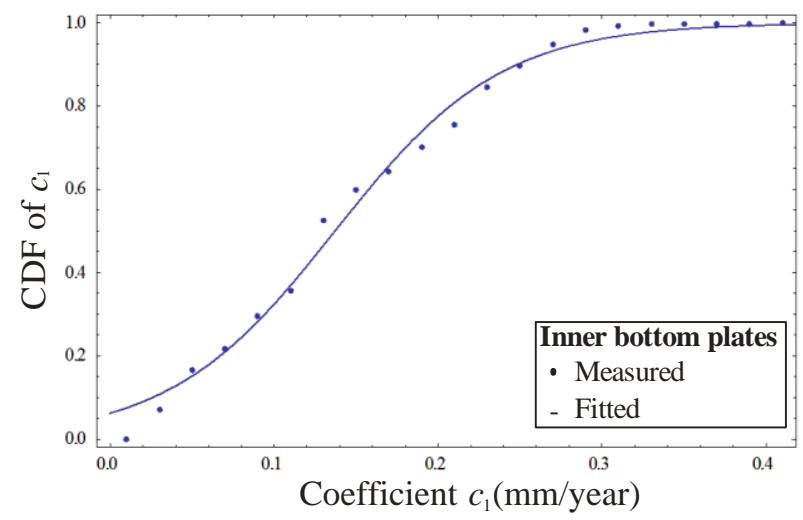

Fig. 10 a) Fitted $\mathrm{CDF}$ of logistic distribution to data in Figure 9

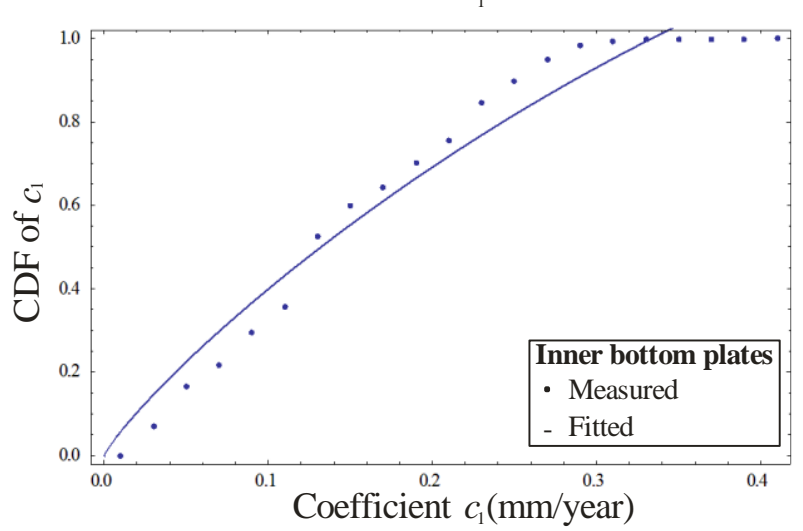

Fig. 10 c) Fitted CDF of beta distribution to data in Figure 9

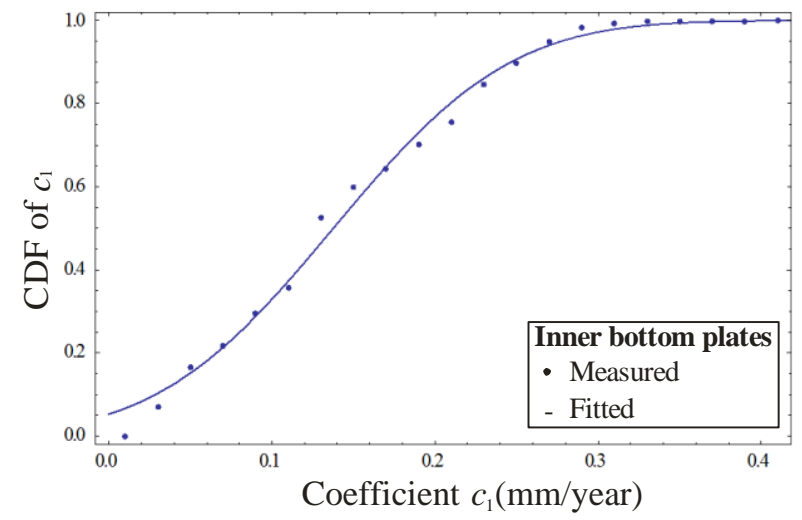

Fig. 10 b) Fitted CDF of normal distribution to data in Figure 9

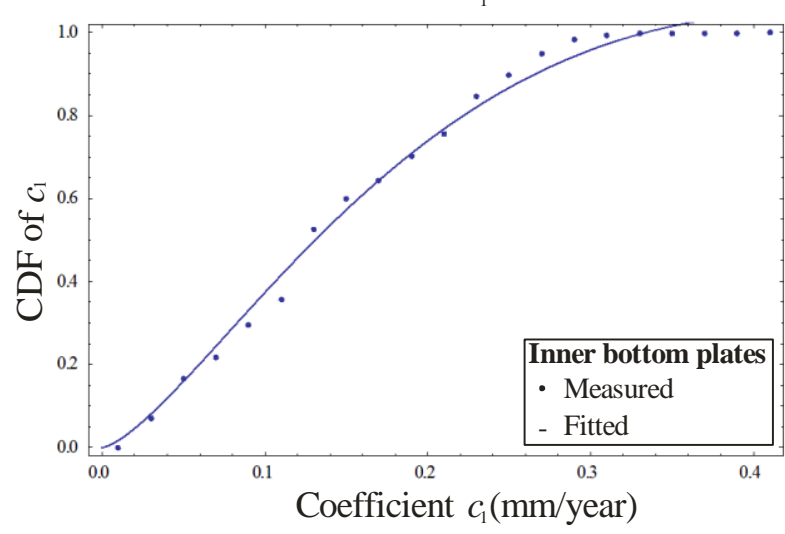

Fig. 10 d) Fitted CDF of gamma distribution to data in Figure 9

The expressions for fitted cumulative distribution function and the probability density function of logistic distribution of $c_{1}$ from Eq. (1), whose CDF is presented in Figure 10 a), are respectively given by

$$
F_{c_{1}}^{(l)}(x)=\frac{1}{1+\exp (-(-0.137133+x) / 0.050494)}=\frac{1}{1+\exp (2.715828-19.804333 x)}
$$

and

$$
f_{c_{1}}(x)=\frac{d}{d x} F_{c_{1}}(x)=\frac{19.804333 \exp (2.715828-19.804333 x)}{(1+\exp (2.715828-19.804333 x))^{2}} .
$$

Then the corresponding mean and standard deviation of the coefficient $c_{1}$ are respectively equal to $\mu_{c_{1}}^{(l)}=0.137133 \mathrm{~mm} /$ year and $\sigma_{c_{1}}^{(l)}=0.091587 \mathrm{~mm} /$ year. Notice that the previous value $\mu_{c_{1}}^{(l)}=0.137133$ is very close to the corrosion rate $r(t)=0.135474$ arising from the linear fitted model for $d(t)$ given by Eq. (2).

Furthermore, the expressions for fitted cumulative distribution function and the probability density function of normal distribution of $c_{1}$ from Eq. (1), whose CDF is presented in Figure 10 b), are respectively given by 
An approach to the probabilistic corrosion rate estimation model for inner bottom plates of bulk carriers
Špiro Ivošević, Romeo Meštrović, Nataša Kovač

$$
F_{c_{1}}^{(n)}(x)=4.689687 \int_{-\infty}^{x} \exp \left(-69.093558(t-0.137615)^{2}\right) d t
$$

and

$$
f_{c_{1}}(x)=4.689687 \exp \left(-69.093558(x-0.137615)^{2}\right) .
$$

Then the corresponding mean and standard deviation of the coefficient $c_{1}$ are given respectively as $\mu_{c_{1}}^{(n)}=0.137165 \mathrm{~mm} /$ year and $\sigma_{c_{1}}^{(n)}=0.085068 \mathrm{~mm} /$ year. As previously noted, it can be observed that the value $\mu_{c_{1}}^{(n)}=0.137165$ is very close to the corrosion rate $r(t)=0.135474$ arising from the linear fitted model for $d(t)$ given by Eq. (2).

Some empirical values and fitted values of cumulative distribution functions of logistic and normal distribution of $c_{1}$ which are defined by Eq. (8) and Eq. (10), respectively, are given in Table 2.

Table 2 The empirical values and fitted values of CDF for $c_{1}$

\begin{tabular}{|c|c|c|c|c|c|c|c|}
\hline $\mathrm{x}$ & $\begin{array}{c}\text { Empirical } \\
\text { CDF of } c_{1}\end{array}$ & $F_{c_{1}}^{(l)}(x)$ & $F_{c_{1}}^{(n)}(x)$ & $\mathrm{x}$ & $\begin{array}{c}\text { Empirical } \\
\text { CDF of } c_{1}\end{array}$ & $F_{c_{1}}^{(l)}(x)$ & $F_{c_{1}}^{(n)}(x)$ \\
\hline 0.01 & 0.000000 & 0.074622 & 0.066784 & 0.23 & 0.845614 & 0.862849 & 0.861269 \\
\hline 0.03 & 0.070175 & 0.107007 & 0.102923 & 0.25 & 0.898246 & 0.903370 & 0.906774 \\
\hline 0.05 & 0.164912 & 0.151151 & 0.151515 & 0.27 & 0.949123 & 0.932850 & 0.940177 \\
\hline 0.07 & 0.217544 & 0.209240 & 0.213351 & 0.29 & 0.982456 & 0.953797 & 0.963383 \\
\hline 0.09 & 0.294737 & 0.282229 & 0.287829 & 0.31 & 0.992982 & 0.968431 & 0.978642 \\
\hline 0.11 & 0.356140 & 0.368805 & 0.372732 & 0.33 & 0.998246 & 0.978534 & 0.988139 \\
\hline 0.13 & 0.526316 & 0.464743 & 0.464336 & 0.35 & 0.998246 & 0.985452 & 0.993732 \\
\hline 0.15 & 0.598246 & 0.563363 & 0.557879 & 0.37 & 0.998246 & 0.990163 & 0.996851 \\
\hline 0.17 & 0.642105 & 0.657214 & 0.648289 & 0.39 & 0.998246 & 0.993359 & 0.998496 \\
\hline 0.19 & 0.701754 & 0.740196 & 0.730992 & 0.41 & 1.000000 & 0.995521 & 0.999318 \\
\hline 0.21 & 0.754386 & 0.808930 & 0.802595 & 0.43 & 1.000000 & 0.996982 & 0.999706 \\
\hline
\end{tabular}

3.3 Another statistical approach to the examination of best fitted distribution of corrosion rate $c_{1}$

In Subsection 3.2, under a set of 570 measurements of plate thickness due to corrosion, $d(t)$ (depth of corrosion at age $t$, in $\mathrm{mm}$ ), for inner bottom plates of 38 ship's surveys, it can be established that one of the following random continuous distributions: normal distribution, logistic distribution, beta distribution or gamma distribution, should be a good candidate for best fitted distribution for the constant $c_{1}$ involving in the fitted linear model for $d(t)$ expressed as:

$$
d(t)=\mathrm{c}_{1}(t-4) .
$$

By using this, and the obtained expressions for CDF and probality density function (in the sequel, briefly denoted as PDF) of the previously mentioned four distributions, the possible goodness of these fitted distributions in terms of their PDF is examined here. By applying 
Anderson-Darling test to the sorted values of $\mathrm{c}_{1}=d(t) /(t-4)$ with frequencies presented in Figure 7 (related to a set of 570 measurements data of plate thickness due to corrosion), the positive $\mathrm{p}$ - values of this test is obtained only in the following two cases:

a) the case of logistic distribution with mean 0.137133 and scale parameter 0.050494 .

Notice that the above logistic distribution coincides with those obtained in Subsection, 3.2 whose $\mathrm{CDF}$ is given by the expression (8).

Graphics of PDF of this logistic distribution together with related empirical PDF is presented in Figure 11.

b) the case of normal distribution with mean 0.137615 and standard deviation 0.085070 .

Notice that the above normal distribution coincides with those obtained in Subsection 3.2 whose CDF is given by the expression (10).

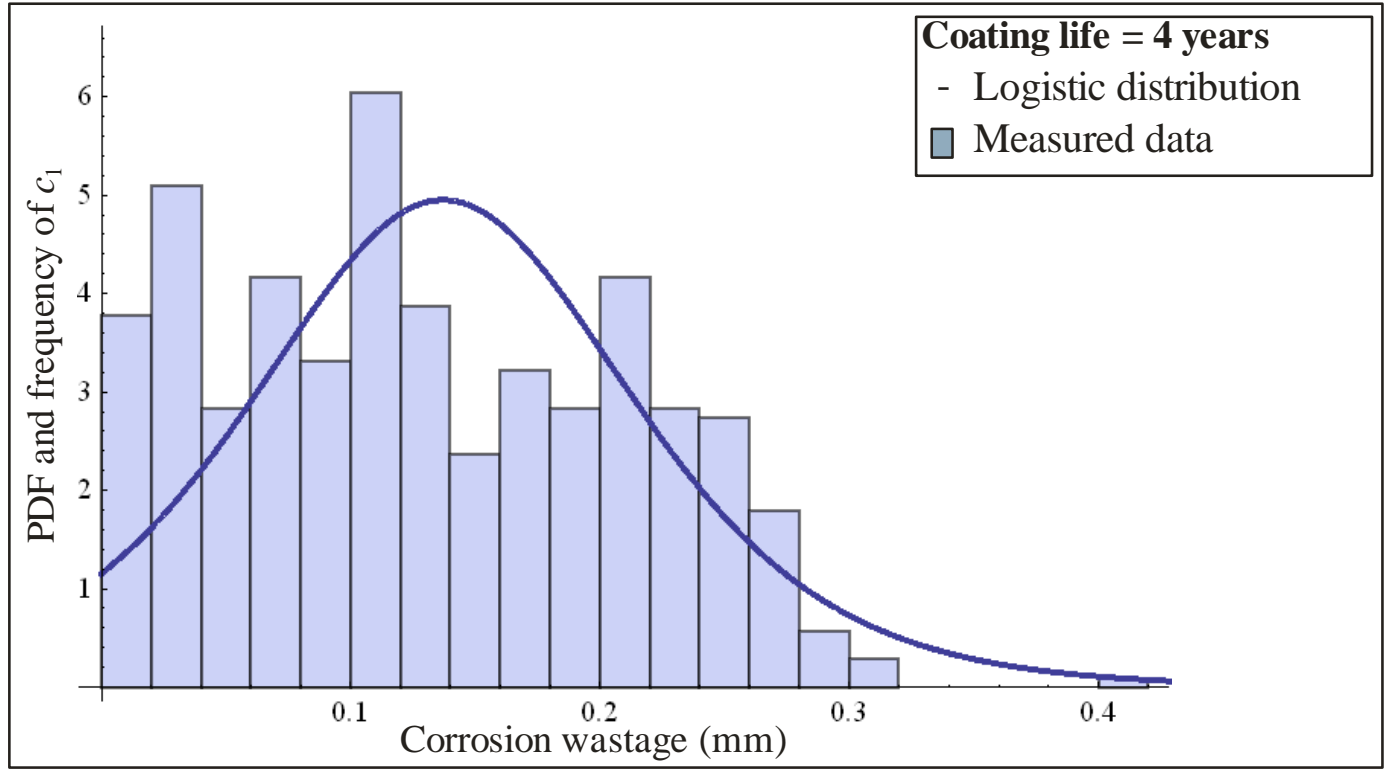

Fig. 11. Empirical PDF and graphic of PDF of fitted logistic distribution

Hence, the logistic distribution or normal distribution would be well appropriate for the probabilistic corrosion rate estimation model for inner bottom plates of bulk carriers.

\section{Conclusion}

The analytical and probabilistic corrosion rate estimation models for different hull structure elements of bulk carriers have been extensively investigated by many authors during the last two decades. Motivated by these investigations, this paper studies the probabilistic corrosion rate estimation model related only to inner bottom plates of bulk carriers. More precisely, by using the set of data consisting of 570 measurements of corrosion wastage for inner bottom plates of 38 ships surveys, this paper examines the cumulative density function for the constant (considered as a continuous random variable) $c_{1}$ from the obtained fitted linear model for corrosion wastage given by the expression $d(t)=c_{1}(t-4)$. In other words, the distribution of corrosion rate concerning inner bottom plates of the each of 38 ships surveys is approximated. The statistical, graphical and numerical results obtained in software Mathematica 9 show that the logistic distribution or normal distribution should be very appropriate for probabilistic corrosion rate estimation model related to inner bottom plates of bulk carriers. Namely, in Section 3, by applying Anderson-Darling test, it is showed that 
An approach to the probabilistic corrosion rate estimation model for inner bottom plates of bulk carriers
Špiro Ivošević, Romeo Meštrović, Nataša Kovač

under collection of mentioned set of 570 measurements data, the good candidates for the cumulative density function of $c_{1}$ between numerous continuous random variables are only the logistic and normal distribution. Accordingly, it is believed that under a larger set of mentioned measurements, this hypothesis will be confirmed in some future investigations with a good confidence level.

\section{Acknowledgement}

This research work has been supported by the INVAR-Ivošević Company. Some more information about the Company can be found at URL: http://www.invar.me/index.html. Namely, the data collected and systematized during the last twenty-five years by the Company operators and experts have been included into the above presented simulation and probabilistic analysis of the corrosion effects to the analyzed group of ten aged bulk carriers fuel tanks. It is to be pointed out that the INVAR-Ivošević Company provides its customers with marine services of ultrasonic thickness measurements of vessels' hull structures and it has seven valid certificates issued by recognized classification societies: LR, BV, DNV, GL, RINA, ABS and NKK. Currently, more than three hundred vessels, mainly aged bulk carriers, are being inspected by the Company.

\section{REFERENCES}

[1] Paik, J.F., Brennan, F., Carlsen, C.A., Daley, C., Garbatov, Y., Ivanov, L., Rizzo, C., Simonsen, B.C, Yamamoto, N., Zhuang H. Z., Report of Committee V.6 Condition Assessment of Aging Ships, 16th International Ship and Offshore Structures Congress, 20-25 August 2006, Southampton, UK.

[2] Roberts, S.E., Marlow, P.B., Casualties in dry bulk shipping (1963-1996), Marine Policy, vol. 26, 2002, pp. 437-450. https://doi.org/10.1016/S0308-597X(02)00024-6.

[3] Bulk carrier casualty report, IMO, MSC 83/INF.6, 3 July 2007.

[4] Paik, J.K., Kim, S.K., Lee, S.K., A probabilistic corrosion rate estimation model for longitudinal strength members of bulk carriers, Ocean Engineering, vol. 25, no. 10, 1998, pp. 837-860. https://doi.org/10.1016/S0029-8018(97)10009-9.

[5] Guedes Soares, C., Garbatov, Y., Zayed, A., Effect of environmental factors on steel plate corrosion under marine immersion conditions, Corrosion Engineering, Science and Technology, vol. 46, 2011, pp. 524-541. https://doi.org/10.1179/147842209X12559428167841.

[6] Paik, J.K., Thayamballi, A.K., Park, Y.I., Hwang, J.S., A time-dependent corrosion wastage model for seawater ballast tank structures of ships, Corrosion Science, vol. 46, no. 2, 2004, pp. 471-486. https://doi.org/10.1016/S0010-938X(03)00145-8.

[7] Yamamoto, N., Ikagaki, K., A Study on the Degradation of Coating and Corrosion on Ship's Hull Based on the Probabilistic Approach, Journal of Offshore Mechanics and Arctic Engineering, vol. 120, 1998, pp. 121-128. https://doi.org/10.1115/1.2829532.

[8] Guo, J., Wang, G., Ivanov, L., Perakis, A.N., Time-varying ultimate strength of aging tanker deck plate considering corrosion effect, Marine Structures, vol. 21, no. 4, 2008, pp. 402-419. https://doi.org/10.1016/j.marstruc.2008.03.002.

[9] Garbatov, Y., Guedes Soares, C., Wang, G., Non-linear time dependent corrosion wastage of deck plates of ballast and cargo tanks of tankers, 22nd International Conference on Offshore Mechanics and Arctic Engineering, OMAE 2005-67579, Halkidiki, Greece, 12-17th June, 2005.

[10] Jurišić, P., Parunov, J., Garbatov, Y., Aging effects on Ship Structural integrity, Brodogradnja, vol. 68, no. 2, 2017, pp.15-28. https://doi.org/10.21278/brod68202.

[11] Jurišić, P., Parunov, J., Garbatov, Y., Comparative analysis based on two nonlinear corrosion models commonly used for prediction of structural degradation of oil tankers, Transactions of FAMENA, vol. 38, no. 2, 2014, pp.21-30.

[12] Paik, J.K., Lee, J.M., Park, Y.I., Hwang J.S., Kim, C.W., Time-variant ultimate longitudinal strength of corroded bulk carriers, Marine Structures, vol. 16, 2003, pp. 567-600. https://doi.org/10.1016/j.marstruc.2004.01.003. 
Špiro Ivošević, Romeo Meštrović, Nataša Kovač
An approach to the probabilistic corrosion rate estimation model for inner bottom plates of bulk carriers

[13] Paik, J.K., Thayamballi, A.K., Park, Y.I., Hwang, J.S., A time-dependent corrosion wastage model for bulk carrier structures, International Journal of Maritime Engineering, vol. 145, Part A2, 2003, pp. 61-87.

[14] Bauk, S., Aleksić, M., Ivošević, Š., Scanning the fuel tanks' Corrosion Wastage of Some Aged Bulk Carriers Due to Security Reasons, PROMET - Traffic \& Transportation, vol. 23, no. 6, 2011, pp. 459470.

[15] Paik J.K., Corrosion Analysis of Seawater Ballast Tank Structures, International Journal of Maritime Engineering, vol. 146, Part A1, 2004, pp. 1-12. https://doi.org/10.3940/rina.ijme.2004.a1.804.

[16] Norhazilan, M.N., Smith, G.H., Yahaya N., The Weibull time-dependent growth model of marine corrosion in seawater ballast tank, Malaysian Journal of Civil Engineering, vol. 19, no. 2, 2007, pp. 142155.

[17] Qin , S., Cui, W., Effect of corrosion models on the time-dependent reliability of steel plated elements, Marine Structures, vol. 16, 2003, pp. 15-34. https://doi.org/10.1016/S0951-8339(02)00028-X.

[18] Paik, J.K., Thayamballi, A.K., Ultimate strength of aging ships, Journal of Engineering for the Maritime Environment, vol. 1, no. 1, 2002, pp. 57-77.

[19] Guedes Soares, C, Garbatov Y., Reliability of maintained ship hulls subjected to corrosion, Journal of Ship Research, vol. 40, no. 3, 1996, pp. 235-243.

[20] Guedes Soares, C., Garbatov Y., Reliability of maintained ship hull girders subjected to corrosion and fatigue, Structural Safety, vol. 20, 1998, pp. 201-19. https://doi.org/10.1016/S0167-4730(98)00005-8.

[21] Guedes Soares, C., Garbatov, Y., Reliability of plate elements subjected to compressive loads and accounting for corrosion and repair. In: Shiraishi N., Shinozuka M., Wen, Y.K., Structural safety and Reliability, vol. 3. Rotterdam: Balkema, 1998. pp. 2013-20.

[22] Guedes Soares, C, Garbatov, Y., Reliability of corrosion protected and maintained ship hulls subjected to corrosion and fatigue, Journal of Ship Research, vol. 43, no. 2, 1998, pp. 65-78.

[23] Guedes Soares, C, Garbatov Y., Reliability of maintained ship hulls subjected to corrosion and fatigue under combined loading, Journal of Constructional Steel Research, vol. 52, 1999, pp. 93-115. https://doi.org/10.1016/S0143-974X(99)00016-4.

[24] Yamamoto, N, Kumano, A., Matoba, M., Effect of corrosion and its protection on hull strength (2nd report), Journal of the Society of Naval Architects of Japan, vol. 176, 1994, pp. 281-289. https://doi.org/10.2534/jjasnaoe1968.1994.176_281.

[25] Yamamoto, N., Ikegami, K., A study on the degradation of coating and corrosion of ship's hull based on the probabilistic approach. In: Proceedings of the International Offshore Mechanics and Arctic Engineering Symposium (OMAE’96), vol. 2, 1996, pp. 159-166.

Submitted: $\quad$ 06.04.2017. $\quad$ Ass. Prof. Špiro Ivošević, $\underline{\text { spiroi@ac.me }}$

Prof. Dr. Romeo Meštrović, romeo@ac.me

Accepted: $\quad$ 28.08.2017.

Mr. Nataša Kovač, knatasa@ac.me

University of Montenegro , Maritime Faculty Kotor,

Dobrota 36, Kotor, Montenegro 